\title{
Predator dependent mimetic complexes: Do passerine birds avoid Central European red-and-black Heteroptera?
}

\author{
KateŘina HOTOVÁ SVÁdOVÁ, Alice EXNEROVÁ, Michala KOPEČKOVÁ and Pavel ŠTYS
}

Department of Zoology, Faculty of Science, Charles University, Viničná 7, CZ-128 44 Praha 2, Czech Republic; e-mails:
K.Svadova@seznam.cz; exnerova@gmail.com; misa.kopeckova@seznam.cz; pavelstys@gmail.com

Key words. Aposematism, true bugs, Heteroptera, avian predators, mimetic complex

\begin{abstract}
True bugs are generally considered to be well protected against bird predation. Sympatric species that have similar warning coloration are supposed to form a functional Müllerian mimetic complex avoided by visually oriented avian predators. We have tested whether these assumptions hold true for four species of European red-and-black heteropterans, viz. Pyrrhocoris apterus, Lygaeus equestris, Spilostethus saxatilis, and Graphosoma lineatum. We found that individual species of passerine birds differ in their responses towards particular bug species. Great tits (Parus major) avoided all of them on sight, robins (Erithacus rubecula) and yellowhammers (Emberiza citrinella) discriminated among them and attacked bugs of some species with higher probability than others, and blackbirds (Turdus merula) frequently attacked bugs of all the tested species. Different predators thus perceive aposematic prey differently, and the extent of Batesian-Müllerian mimetic complexes and relations among the species involved is predator dependent.
\end{abstract}

\section{INTRODUCTION}

Unpalatable animals usually use warning signals to discourage predators from attacking them. Warning coloration is an essential warning signal for avian predators that discriminate among the various preys mainly on the basis of visual cues (Avery \& Nelms, 1990; Roper, 1990). Two or more unpalatable species may have evolved mutual resemblance, forming thus a mimetic complex. Several types of mimetic relationships between the species involved in the mimetic complex were distinguished, viz. Batesian, quasi-Batesian, quasi-Müllerian, Müllerian and super-Müllerian (Speed, 1999; Balogh et al., 2008). Their classification depends on the level of mutual similarity of the species involved and on presence, type and efficiency of their defensive mechanisms.

There are many theoretical studies and mathematical models focused on mimicry (Speed, 1993, 1999; Balogh \& Leimar, 2005; Balogh et al., 2008; Ruxton et al., 2008; Sherratt, 2008) but only few experimental studies. Most of the experiments were carried out using artificial prey and a single predator species (e.g., Rowe et al., 2004; Ihalainen et al., 2007). Studies with live aposematic prey used mostly butterflies (Bower, 1958a, b; Ritland, 1991; Miller, 1996; Pinheiro, 2003). However, we can find a number of aposematic species with greatly similar warning pattern among European red-and-black Heteroptera. Although the Heteroptera may form regular part of the diet of some passerine birds (e.g. Heikertinger, 1922; Betts, 1955; Exnerová et al., 2003b), the aposematic species are usually avoided (Schlee, 1986; Sillén-Tullberg, 1985; Ribeiro, 1989; Exnerová et al., 2003a, 2007). It is generally understood that red-and-black Heteroptera form mimetic complexes (see Schuh \& Slater, 1995), although their nature, extent, model-mimic relationships and in some cases their very existence are often suspect and mostly lack experimental evidence. Only few comparative studies on several different live aposematic heteropteran species tested with same predators were carried out (Schlee, 1986; Evans et al., 1987; Gamberale-Stille \& Tullberg, 1999; Tullberg et al., 2000). Exnerová et al. (2003a, 2007) showed differences among bird predators in reactions to aposematic prey; consequently, we can assume that also mimetic complexes could be predator dependent. This may be the reason why the results of experiments performed with bird predators and living insect prey were ambiguous, as to the degree of similarity between the appearances of two aposematic species, which is required for their mutual protection (Evans et al., 1987 contra Sillén-Tullberg et al., 1982). We cannot observe avoidance learning or generalization under natural conditions but we can observe the results in behaviour of wild-caught birds. In this study, we investigated reactions of four passerine bird species towards four red-and-black warningly coloured species of true bugs common in Central Europe.

The true bugs living in Central Europe include many species with warning red-and-black coloration in adult stage. They belong to infraorders Cimicomorpha (Nabidae, Reduviidae, Miridae) and Pentatomomorpha (Lygaeidae, Oxycarenidae, Pyrrhocoridae, Rhopalidae, Pentatomidae). The four pentatomomorphan species chosen for experiments (namely Lygaeus equestris, Spilostethus saxatilis, Pyrrhocoris apterus, Graphosoma lineatum) occur frequently at many localities, are likely to be encountered by insectivorous birds owing to exposed way of life, are of the same size, and represent the aposematically most affected family Lygaeidae as well as two other only distantly related clades (Pyrrhocoridae and Pentatomidae, respectively). We have excluded some 
similarly frequent mirids owing to universally different general facies and Eurydema spp. because of reduced chemical defence mechanisms.

The four bird species represent passerines of various body size and different trophic biology, and they were chosen on the basis of results from the previous comparative study (Exnerová et al., 2003a): they differed in their reactions to the aposematic and artificially nonaposematic (brown-painted) P. apterus. Great tits (Parus major L., 1758) and robins (Erithacus rubecula (L., 1758)) avoided attacking red-and-black $P$. apterus but did not avoid the brown-painted individuals. Yellowhammers (Emberiza citrinella L., 1758) and blackbirds (Turdus merula L., 1758) attacked both colour forms of P. apterus frequently, and we chose them to test whether the other red-and-black true bugs deter predators more effectively.

In the present experiments we tested: (i) Whether all the tested bug species are equally well protected and consequently avoided by birds, or their degree of protection is different and the birds discriminate among them. (ii) Whether different bird species react similarly to the potential mimetic complex or the extent of the complex is predator dependent.

\section{MATERIAL AND METHODS}

\section{Prey}

We experimented with four species of adult red-and-black true bugs (Hemiptera: Heteroptera) from the clade Pentatomomorpha: Lygaeidae: Lygaeinae: Lygaeus equestris (L., 1758; Fig. 1a), Spilostethus saxatilis (Scopoli, 1763; Fig. 1b); Pyrrhocoridae: Pyrrhocoris apterus (L., 1758; Fig. 1c); Pentatomidae: Podopinae: Graphosoma lineatum (L., 1758; Fig. 1d). All the species are common in Central Europe, and they may occur syntopically at some localities. They are all phytophagous and herbicolous, with the exception of mainly epigeic P. apterus. $L$. equestris feeds mainly on Vincetoxicum hirundinaria and Adonis spp. (Wachmann et al., 2007); we collected the bugs on $V$. hirundinaria. S. saxatilis is polyphagous but develops and feeds mainly on Colchicum autumnale (Wachmann et al., 2007), which was the host plant of bugs used in our experiments. $P$. apterus is common on Tilia spp. but feeds also on various Malvaceae and Robinia pseudacacia (Wachmann et al., 2007); we collected the bugs living on Tilia cordata. Host plants of $G$. lineatum are various species of Apiaceae (Wachmann et al., 2008); experimental bugs were collected from Anthriscus sylvestris and Daucus carota. All the bug species are of similar body length (Wagner, 1966) - L. equestris: 11-12 mm, S. saxatilis: 10-11 mm, P. apterus: 10-12 mm, G. lineatum: 8-12 mm. The samples were collected in Prague $(50.08 \mathrm{~N}, 14.24 \mathrm{E})$, Velemín (50.32 N, 13.58 E), S. saxatilis in Lednice (48.49 N, 16.49 E).

The adult heteropterans are provided with metathoracic glands; their secretion usually consists of a complex mixture of dozens of semiochemicals (Aldrich, 1988) with species-specific quantitative and qualitative composition. In all the species studied, the secretion is composed mainly of short-chain aldehydes and hydrocarbons (Farine et al., 1992; Stránský et al., 1998; Šanda et al., in prep). The metathoracic secretion is known to deter predators (Remold, 1963; Schuh \& Slater, 1995) including birds (e.g. Sillén-Tullberg, 1985; Schlee, 1986; Exnerová et al., 2003a); it may even be mildly poisonous or, for small predators like ants, lethal (Remold, 1963; Farine, 1988). Further universal functions of these secretions are pheromonal, bactericidal and
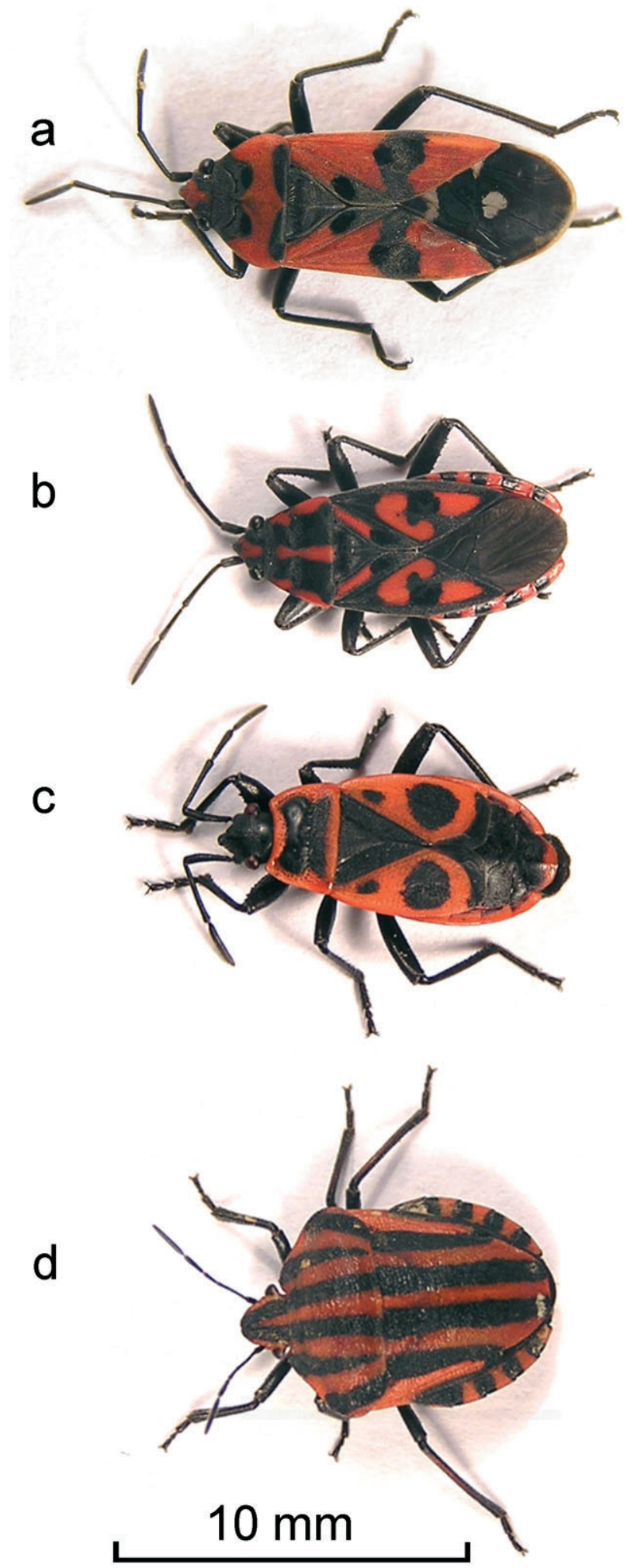

Fig. 1. Experimental prey species: a - Lygaeus equestris (11.3 $\mathrm{mm}) ; \mathrm{b}$ - Spilostethus saxatilis $(10.0 \mathrm{~mm}) ; \mathrm{c}-$ Pyrrhocoris apterus $(10.2 \mathrm{~mm}) ; \mathrm{d}$ - Graphosoma lineatum $(9.2 \mathrm{~mm})$.

fungicidal. The secretion smells strongly to humans in L. equestris, S. saxatilis, and G. lineatum, while it is less odorous in $P$. apterus (pers. observ.), the difference being probably linked to the reduced scent glands and their efferent components in Pyrrhocoridae (Aldrich, 1988). The dorso-abdominal glands per- 
forming the repellent function in larvae are producing pheromones in adults or have become lost.

The bugs were fed with green parts and seeds of their host plants, supplied with water ad libitum, and kept under a long-day photoperiod (18L : 6D) at a temperature of $26 \pm 1{ }^{\circ} \mathrm{C}$.

\section{Predators}

We tested four species of passerine birds: the great tit (Parus major L., 1758; Paridae), the robin (Erithacus rubecula (L., 1758); Turdidae) and the blackbird (Turdus merula L., 1758; Turdidae), which are predominantly insectivorous, and the yellowhammer (Emberiza citrinella L., 1758; Emberizidae), which is insectivorous as well as granivorous. Experiments were carried out during years 2000, 2002-2005 and 2007. We have tested 80 birds of each species, and divided them into four groups of 20 birds, each group tested with different bug species. Sex and age (yearlings versus older birds) of the birds were identified whenever possible. Birds were caught in mist nets at localities around Prague $(50.08 \mathrm{~N}, 14.24 \mathrm{E})$ and Velemín $(50.32 \mathrm{~N}, 13.58 \mathrm{E})$ over the year except the breeding season (May - July). The birds were allowed to habituate to the laboratory conditions for $2-5$ days before testing. The light conditions were set according to the outdoor photoperiod. The birds were offered a diet of mealworms (larvae of Tenebrio molitor L., 1758) and commercial food for insectivorous birds (Vitakraft). As a familiar prey, mealworms were also used for testing foraging motivation of birds in control trials during the experiments.

\section{Ethical note}

We have obtained permission for keeping wild-caught great tits, robins, blackbirds and yellowhammers by Environmental Department of Municipality of Prague and PLA České Středohoří, Czech Republic (6403/304/2004-Fr, MHMP-154521/2004/ OZP-V-1190/R-9/05/Pra) and permission for laboratory experimentation with birds from Czech Animal Welfare Commission (No. 1020/919/A/00, 150/99 and 740/04). Each bird was ringed (licence No. 876 and 967, Czech Ringing Centre Praha) and released back to the locality where it had been caught within few days after the experiment.

\section{Experimental design}

We carried out the experiments in wooden cages $(70 \times 70 \times$ $70 \mathrm{~cm}$ ) equipped with a perch, a dish with water and a rotating beige wooden feeding tray with five cups. We observed the birds through a one-way window. The cage was illuminated by daylight-simulating Biolux Combi 18W bulb (Osram). Birds were deprived of food for $2 \mathrm{~h}$ before the experiment.

Each experiment consisted of a series of ten trials, in which the bird was offered one prey item per trial. The sequence started with familiar prey (mealworm) to check the bird's foraging motivation. If the bird consumed the mealworm, the sequence continued with an individual of a particular bug species during every even trial and the mealworm during every odd trial. Each trial was terminated after the bird ate the prey; otherwise it lasted five minutes. Each bird was tested only once, with only one bug species.

\section{Statistics}

For each bird, the data were expressed as presence or absence of (a) attacking (i.e. seizing or pecking) at least one bug during the experiment and (b) killing at least one bug. We used analysis of variance (ANOVA) in general linear modelling (GLM) with binomial distribution and logit link-function (Crawley, 1993) to test effects of species of the true bug, species of bird and the interaction of the factors. In case of significant interaction, we analysed the data for each predator or prey species separately.
Post-hoc comparisons between the factor levels (prey or predator species) were made using Fisher's LSD method.

Blackbird was the only species in which the birds frequently and repeatedly attacked the bugs. It was therefore possible to analyse counts of the bugs that were (a) attacked and (b) killed by one bird, and incorporate also sex and age of the birds into the model. We used analysis of variance (ANOVA) in general linear modelling (GLM) with Poisson distribution and log linkfunction (Crawley, 1993); maximal model was simplified according Mallow's Cp statistics.

All calculations were made in S-plus 4.0 (MathSoft, 1997).

\section{RESULTS}

\section{Proportions of birds attacking the prey}

The proportions of birds that attacked at least one bug were influenced by both bird and bug species and the interaction between the two factors was also significant (glm ANOVA: bird species $\mathrm{F}_{3,316}=10.64, \mathrm{p}<0.001$; bug species $\mathrm{F}_{3,313}=3.11, \mathrm{p}=0.027$; interaction $\mathrm{F}_{9,304}=2.24$, $\mathrm{p}=0.019$; Fig 2). We have therefore carried out separate analyses for individual bird species.

In great tits (Parus major) and blackbirds (Turdus merula), bug species did not influence proportions of birds that attacked at least one bug during the experiment (glm ANOVA: for great tits $\mathrm{F}_{3,76}=2.90, \mathrm{p}=0.137$; for blackbirds $\mathrm{F}_{3,76}=0.41, \mathrm{p}=0.749$ ). Great tits mostly avoided all prey species. In contrast, blackbirds attacked bugs of all the species often and with equal probability (Fig. 2). Bug species influenced the proportions of robins (Erithacus rubecula; glm ANOVA: $\mathrm{F}_{3,76}=4.54, \mathrm{p}=$ 0.006) and yellowhammers (Emberiza citrinella; glm ANOVA: $\left.\mathrm{F}_{3,76}=3.03, \mathrm{p}=0.035\right)$ that attacked at least one bug. Robins attacked Pyrrhocoris apterus with higher probability than Spilostethus saxatilis and Lygaeus equestris (Fisher LSD test). Yellowhammers attacked $P$. apterus and L. equestris with higher probability than Graphosoma lineatum (Fisher LSD test).

\section{Proportions of birds killing the prey}

The proportions of birds that killed at least one bug during the experiment differed among bird species (glm ANOVA: $F_{3,316}=24.40, p<0.001$, Fig. 2) but were not influenced by the bug species $\left(\mathrm{F}_{3,313}=1.49, \mathrm{p}=0.217\right)$; there was significant interaction between the two factors $\left(\mathrm{F}_{9,304}=2.57, \mathrm{p}=0.007\right)$. We have therefore carried out separate analyses for individual bug species. The effect of bird species on the proportion of individuals that killed at least one bug was significant also in these separate analyses (glm ANOVA: for L. equestris $\mathrm{F}_{3,76}=9.46, \mathrm{p}<$ 0.001 ; for $S$. saxatilis $\mathrm{F}_{3,76}=5.80, \mathrm{p}=0.001$; for $G$. lineatum $\mathrm{F}_{3,76}=9.43, \mathrm{p}<0.001$; for P. apterus $\mathrm{F}_{3,76}=8.13$, $\mathrm{p}<0.001$ ), but the differences between the bird species were slightly different for each species of the bugs. None of the great tits or robins killed any L. equestris, but these bugs were killed by some blackbirds and yellowhammers. $S$. saxatilis was killed with higher probability by blackbirds than by robins (Fisher LSD test). Blackbirds killed $P$. apterus with higher probability than great tits and robins (Fisher LSD test) and the probability they killed $G$. lineatum was higher than for the other bird species (Fisher LSD test). 

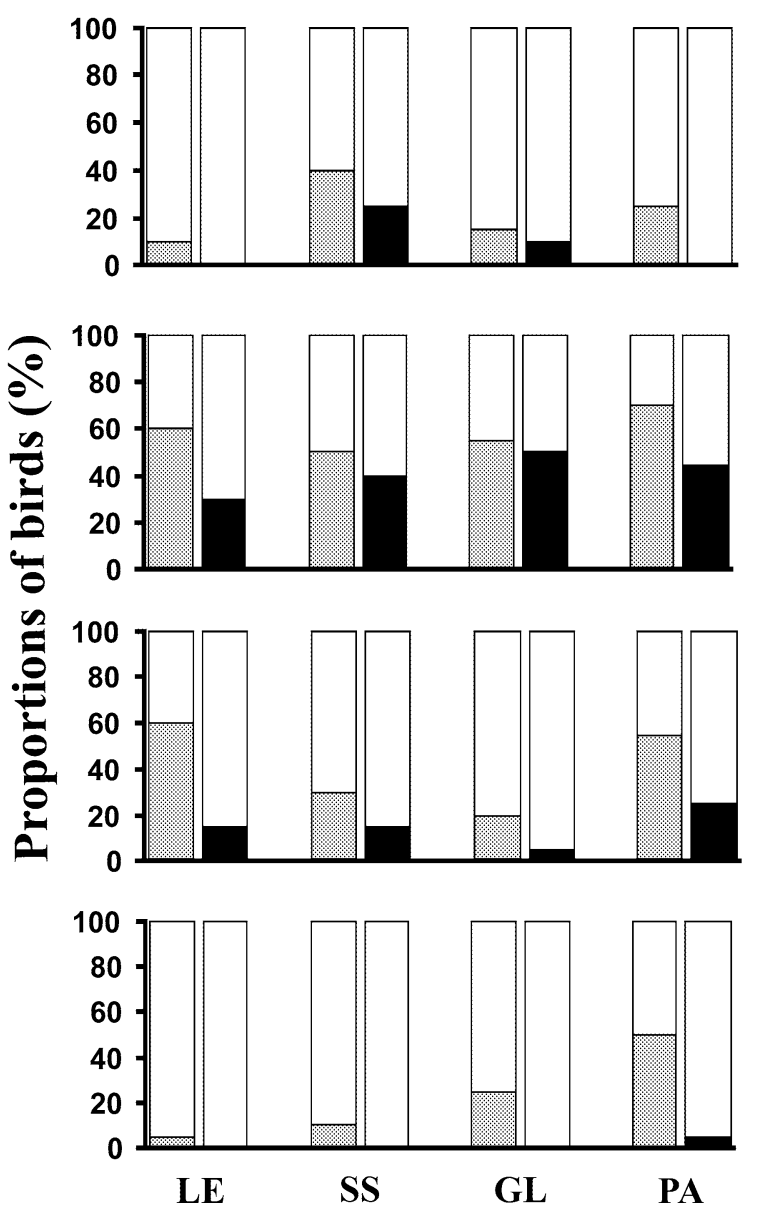

Fig. 2. Proportions of a) great tits, b) blackbirds, c) yellowhammers, and d) robins that handled (grey part of bars) and killed (black part of bars) at least one bug. Total number of tested birds is 20 per each group. LE groups of birds were tested with Lygaeus equestris, SS with Spilostethus saxatilis, GL with Graphosoma lineatum and PA with Pyrrhocoris apterus.

\section{Variation in reactions of blackbirds}

About half of the blackbirds attacked the bugs during the experiments, and many birds attacked several individual bugs. We found a significant effect of the bug species on the counts of bugs that were attacked and killed by an individual blackbird (glmANOVA: attacking $\mathrm{F}_{3,76}=$ 4.29, $\mathrm{p}=0.007$; killing $\mathrm{F}_{3,76}=5.21, \mathrm{p}=0.003$; Fig. 3 ), but no effect of age or sex of the birds (glmANOVA for attacking: deletion test of sex $\mathrm{F}_{1,74}=0.02, \mathrm{p}=0.880$; deletion test of age $F_{1,75}=1.50, p=0.225$; for killing: deletion test of sex $F_{1,74}=0.001, p=0.969$; deletion test of age $\left.\mathrm{F}_{1,75}=0.45, \mathrm{p}=0.506\right)$. The bugs were repeatedly attacked and killed not only by yearlings but also by older birds.

Significantly more individuals of $P$. apterus and $G$. lineatum than those of $L$. equestris and $S$. saxatilis were attacked by blackbirds. Counts of bugs killed by an individual blackbird were significantly higher for $G$. lineatum than for $L$. equestris and S. saxatilis, and higher for $P$. apterus than for L. equestris (Fig. 3). All individuals of $G$. lineatum that were killed by the blackbirds were also consumed; seven blackbirds, each killed and consumed

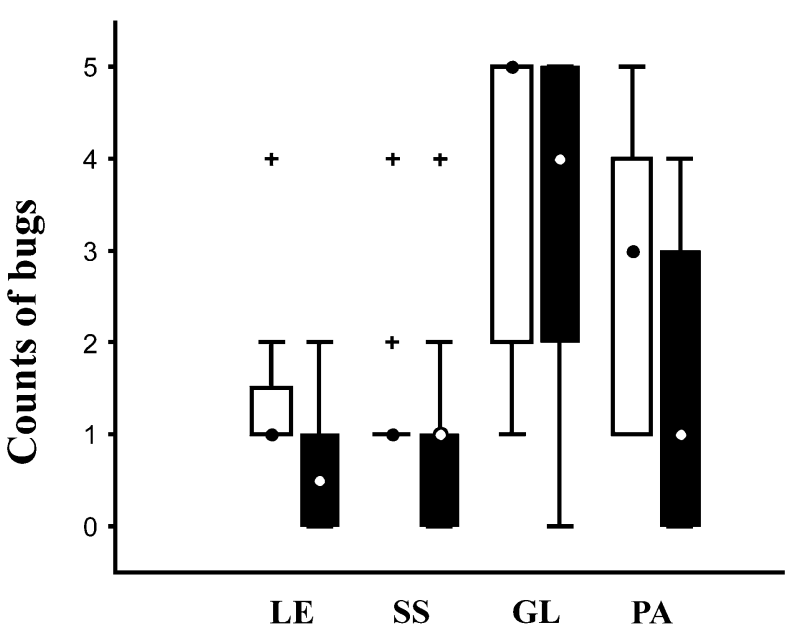

Fig. 3. Counts of bugs that were handled (white bars) and killed (black bars) by one individual blackbird. Only the data from birds that handled at least one bug are provided. Total number of blackbirds that handled at least one bug: 12 for Lygaeus equestris (LE), 11 for Spilostethus saxatilis (SS), 11 for Graphosoma lineatum (GL) and 14 for Pyrrhocoris apterus (PA). Point - median, box - lower and upper quartile (interquartile range), whiskers - non-outlier range (values within 1 times the inter-quartile range outside the closest hinge), crosses - outliers.

four or all five individuals. In contrast, only half of the killed individuals of $P$. apterus were consumed, and $L$. equestris and $S$. saxatilis were consumed only exceptionally.

\section{DISCUSSION}

The birds we tested were wild-caught and hence potentially experienced with a variety of natural prey, probably including aposematic insects as well. Probability that the bird had already encountered a particular bug species before the experiment, differed among the four species of bugs. Our experimental birds were more likely to be experienced with $P$. apterus and $G$. lineatum than with $L$. equestris and $S$. saxatilis, because the latter two are closely associated with their host plants and, consequently, the distribution of these bugs is restricted.

\section{Predator dependent mimetic complex}

Individual species of passerine birds differed in their responses towards a particular bug species. This result indicates that different predators perceive the particular aposematic prey species as well as the mimetic complexes differently.

Consequently, the extent of mimetic complexes and relations among the species involved is apparently predator dependent. In the mimetic complex of European red-and-black true bugs, at least three types of avian predators exist. (1) Broadly generalizing predators avoiding all the prey species involved are represented by great tits. Wild-caught great tits avoided all four species of true bugs. It is unlikely that all the tested birds had encountered all the tested bug species in the wild before the experiments. Therefore we assume that great tits are 
either unable to discriminate among bug species, or more likely, they generalize broadly among them. In any case, the nature of the mimetic complex studied was Müllerian for the great tits. (2) Narrowly generalizing predators discriminating among (at least some) species involved in the potential mimetic complex are represented by robins and yellowhammers. Although all the bug species appeared to be well defended (unpalatable) for robins and yellowhammers, the birds did not react to their visual signals in the same way, and attacked some species more then others. (3) Predators relatively resistant to chemical defence of some of the prey species involved in the potential mimetic complex are represented by blackbirds. The same proportion of blackbirds avoided all the bug species. This indicates rather broad generalization of the visual appearance of the bugs. However, the reactions of those blackbirds that attacked the bugs, differed according to bug species. Some bugs (Graphosoma lineatum and Pyrrhocoris apterus) were found rather palatable and killed and eaten repeatedly, while others (Lygaeus equestris and Spilostethus saxatilis) were dropped. For blackbirds, the mimetic complex is quasi-Batesian or quasi-Müllerian (sensu Balogh et al., 2008). Some species in the complex are less defended than others and may thus play a role of their quasi-Batesian (or even Batesian) mimics.

The importance of different behaviour in broadly and narrowly generalizing predators to the process of evolution of mimicry has been predicted by several theoretical models (e.g. Balogh \& Leimar, 2005; Ruxton et al., 2008). Our results suggest that considerable differences may exist even among wild-caught and potentially experienced birds in their reactions to individual prey species within an apparent mimetic complex as seen by human eyes. These differences mainly relate to how broadly the birds generalize among similar prey species and how resistant they could be against the defensive mechanisms of the prey.

\section{Palatability of red-and-black bugs}

Exnerová et al. (2003a, 2007) showed that great tits and robins avoided red-and-black individuals of Pyrrhocoris apterus more frequently than brown-painted ones while yellowhammers and blackbirds attacked both forms in nearly equal frequencies. Similarly, great tits and robins killed nearly none of the $P$. apterus in present experiments. However, robins as well as yellowhammers attacked $P$. apterus with higher probability than the other bug species. It seems that $P$. apterus is probably not dangerous to handle, which could be linked with reduced scent glands of this species. However, P. apterus is probably dangerous to eat. If swallowed, it frequently caused an apparent discomfort and nausea in robins and great tits (see also Exnerová et al., 2003a).

Both naive and wild-caught birds were tested in experiments with Lygaeus equestris previously (hand-reared great tits by Sillén-Tullberg, 1985, domestic chicks by Tullberg et al., 2000, and wild-caught great tits by SillénTullberg et al., 1982 respectively). Naive birds usually learned to avoid this species after few encounters (SillénTullberg, 1985) and wild-caught birds avoided it (Sillén-
Tullberg et al., 1982). We have found the same in great tits and robins in our experiments, whereas half of yellowhammers and blackbirds attacked L. equestris. In those cases, however, the birds usually started to avoid the bugs after one encounter, and in case of yellowhammers, the handling was careful and the bugs usually survived.

Spilostethus saxatilis was tested in experiments involving bird predators for the first time. Blackbirds attacked and killed on average one individual of $S$. saxatilis while other bird species avoided them.

In the study of Schlee (1986), approximately half of the tested blackbirds avoided Graphosoma lineatum as they did in our experiment. Birds of other species avoided this bug even more frequently than blackbirds. Robins probably cannot swallow the whole bug or break its hard cuticle, which provides additional protection. Great tits and yellowhammers are able to crack the cuticle after a period of time-consuming handling. During this time $G$. lineatum can use its chemical defence, which consists not only in releasing the repellent secretion, but frequently also in squirting it into a distance, often hitting the predator and causing irritation in its mouth or eyes. The squirting is apparently effective, because the bird usually drops the bug or throws it aside, and shakes and scratches its head and wipes its bill repeatedly. Similar reactions, possibly also resulting from the birds being sprayed by the secretion, were observed by Schlee (1986) in the behaviour of blackbirds while handling some pentatomids, namely Palomena prasina (L. 1758), Nezara viridula (L. 1758), and G. lineatum. However, blackbirds can overcome $G$. lineatum chemical defence by swallowing the bug quickly before it can discharge its repellent secretion, or by throwing it against the substrate and pushing it around the cage till it releases all of its secretion and cannot spray the bird. These techniques were also observed by Shlee (1986) in blackbirds handling various, mainly non-aposematic, heteropterans.

\section{Behaviour of individual bird species}

\section{Great tits}

Wild-caught great tits avoided all the offered species of bugs. Previous experiments with naive, hand-reared birds demonstrated that great tits do not have any innate bias against red-and-black prey (Exnerová et al., 2007; Svádová et al., 2009) and that strong neophobia occurs only in some individuals depending on their personality (Exnerová et al., 2010). The avoidance of wild-caught birds is based on the individual learning, and could result either from experience with all the bug species used in the experiments, or, more likely, from experience with any unpalatable red-and-black species from the mimetic complex followed by subsequent wide generalization. All the bug species tested are probably unpalatable for great tits.

\section{Robins}

Robins attacked $P$. apterus with higher probability than other bug species. This indicates that robins discriminated among various species of red-and-black aposematic bugs on the basis of their visual signals; at least they distin- 
guished $P$. apterus from the other species. It seems unlikely that robins were inexperienced with $P$. apterus since it is common in the wild. It is more likely that $P$. apterus is less chemically protected against robins than are the other species, and that robins do not avoid coming to close contact with it. In spite of frequent attacking, robins killed practically no bugs. They probably decide about the prey quality in two steps: at first on sight and then while handling it, when they can react to the smell or taste of the defensive secretion. Avian predators are able to detect the level of unpalatability in chemically defended prey by sampling and tasting it (Ritland, 1994; Skelhorn \& Rowe, 2007). In our experiment, some robins rejected the prey after attack, and it survived the attack unharmed. By careful handling the aposematic prey, robins may detect less defended individuals (automimics) in those insect species, where the degree of unpalatability varies owing to sequestration of defensive chemicals from various hostplants. There is a possibility of automimicry in L. equestris (Tullberg et al., 2000) and S. saxatilis (P. Baňař, unpubl. data). In a previous study, we have found that robins handled aposematic prey more carefully than non-aposematic one, and that aposematics often survived the attacks (Exnerová et al., 2006; see also SillénTullberg, 1985).

\section{Yellowhammers}

Yellowhammers discriminated among the four red-andblack species of bugs. They attacked $P$. apterus and $L$. equestris with higher probability than $G$. lineatum. In case of $L$. equestris this could be caused by relatively low probability of previous experience. However, this explanation does not hold for common $P$. apterus. It seems that $P$. apterus is not unpalatable enough to be avoided (see also Exnerová et al., 2003a). Yellowhammers avoided $G$. lineatum, which is common in the localities where yellowhammers were caught. Yellowhammers' abilities to distinguish among different shapes and patterns of bugs should be further studied. Yellowhammers killed bugs only rarely irrespective of tested species.

\section{Blackbirds}

Blackbirds frequently attacked bugs of all the tested species. Although we found no difference in the number of blackbirds that attacked and killed at least one bug, there were differences in numbers of bugs that were attacked and killed by each individual bird. Blackbirds attacked and killed more individuals of $G$. lineatum and $P$. apterus than of $L$. equestris and $S$. saxatilis. The latter two species may be more protected because of presence of poisonous secondary metabolites (cardenolides) sequestered from their host plant (cf. Scudder \& Duffey, 1972). Surprisingly, we found no effect of age on the behaviour of blackbirds. This result contrasts with those of Schlee (1986), who found young blackbirds more prone to attack various species of true bugs. However, since young birds in her study were reared in captivity, they were, unlike our wild-caught birds, inexperienced. There are two possible explanations why the wild-caught blackbirds attacked, killed and consumed bugs so fre- quently. (a) Defensive mechanisms of all tested bugs are not sufficiently effective to discourage blackbirds from the attack. (b) Blackbirds encountered more frequently those species, which appeared to be quite palatable to them ( $P$. apterus and $G$. lineatum) and generalized the experience to the other, unpalatable species (L. equestris and $S$. saxatilis). Moderate palatability of $P$. apterus to blackbirds was also found by Exnerová et al. (2003a).

ACKNOWLEDGEMENTS. We thank P. Baňař for help with collecting bugs and E. Fučíková and P. Fousová for help with catching and taking care of experimental birds. This study was supported by Czech Science Foundation (project 206/07/0507) and Ministry of Education (project 0021620828).

\section{REFERENCES}

AldRich J.R. 1988: Chemical ecology of the Heteroptera. Annu. Rev. Entomol. 33: 211-238.

Avery M.L. \& Nelms C.O. 1990: Food avoidance by redwinged blackbirds conditioned with a pyrazine odor. The Auk 107: 544-549.

Balogh A.C.V. \& Leimar O. 2005: Müllerian mimicry: an examination of Fisher's theory of gradual evolutionary change. Proc. R. Soc. (B) 272: 2269-2275.

Balogh A.C.V., Gamberale-Stille G. \& Leimar O. 2008: Learning and the mimicry spectrum: from quasi-Bates to super-Müller. Anim. Behav. 76: 1591-1599.

BETTS M.M. 1955: The food of titmice in oak woodland. $J$. Anim. Ecol. 24: 282-323.

Bower J.V. 1958a: Experimental studies of mimicry in some north-american butterflies. 1. The Monarch, Danaus plexippus, and Viceroy, Limenitis archippus archippus. Evolution 12: 32-47.

BOWER J.V. 1958b: Experimental studies of mimicry in some north-american butterflies. 2. Battus philenor and Papiliotroilus, P-polyxenes and P-glaucus. Evolution 12: 123-136.

Crawley M.J. 1993: GLIM for Ecologists. Blackwell Science, Oxford, 379 pp.

Evans D.L., Castoriades N. \& Badruddine H. 1987: The degree of mutual resemblance and its effect on predation in young birds. Ethology 74: 335-345.

Exnerová A., Landová E., Štys P., Fuchs R., Prokopová M. \& Cenláriková P. 2003a: Reactions of passerine birds to aposematic and non-aposematic firebug (Pyrrhocoris apterus; Heteroptera). Biol. J. Linn. Soc. 78: 517-525.

Exnerová A., ŠTYs P., Krištín A., Volf O. \& Pudil M. 2003b: Birds as predators of true bugs (Heteroptera) in different habitats. Biologia (Bratislava) 58: 253-264.

Exnerová A., Svádová K., Štys P., Barcalová S., Landová E., Prokopová M., Fuchs R. \& Socha R. 2006: Importance of colour in the reaction of passerine predators to aposematic prey: experiments with mutants of Pyrrhocoris apterus (Heteroptera). Biol. J. Linn. Soc. 88: 143-153.

Exnerová A., Štrys P., Fučíková E., Veselá S., Svádová K., Prokopová M., Jarošík V., Fuchs R. \& Landová E. 2007: Avoidance of aposematic prey in European tits (Paridae): learned or innate? Behav. Ecol. 18: 148-156.

Exnerová A., Hotová Svádová K., Fučíková E., Drent P. \& ŠTYS P. 2010: Personality matters: individual variation in reactions of naive bird predators to aposematic prey. Proc. $R$. Soc. (B): 277: 723-728.

FARINE J.P. 1988: The exocrine glands of Dysdercus cingulatus F. (Heteroptera, Pyrrhocoridae) - morphology and function of adults glands. Ann. Soc. Entomol. Fr. 24: 241-256. 
Farine J.P., Bonnard O., Brossut R. \& Le Quere J.L. 1992: Chemistry of defensive secretions in nymphs and adults of fire bug, Pyrrhocoris apterus L. (Heteroptera, Pyrrhocoridae). J. Chem. Ecol. 18: 1673-1682.

Gamberale-Stille G. \& Tullberg B.S. 1999: Experienced chicks show biased avoidance of stronger signals: an experiment with natural colour variation in live aposematic prey. Evol. Ecol. 13: 579-589.

HeIKERTINGER F. 1922: Sind die Wanzen (Hemiptera: Heteroptera) durch Ekelgeruch geschützt? Biol. Zbl. 42: 441-464.

Ihalainen E., LindströM L. \& Mappes J. 2007: Investigating Müllerian mimicry: predator learning and variation in prey defences. J. Evol. Biol. 20: 780-791.

MathSoft 1997: S-plus 4. Guide to Statistics: Data Analysis. MathSoft Inc., Seattle.

Miller J.S. 1996: Phylogeny of the neotropical moth tribe Josiini (Notodontidae: Dioptinae): A hidden case of Müllerian mimicry. Zool. J. Linn. Soc. 118: 1-45.

Pinheiro C.E.G. 2003: Does Müllerian mimicry work in nature? Experiments with butterflies and birds (Tyrannidae). Biotropica 35: 356-364.

REMOLD H. 1963: Scent-glands of land bugs, their physiology and biological function. Nature 198: 764-768.

Ribeiro S.T. 1989: Group effects and aposematic in Jadera haematoloma (Hemiptera: Rhopalidae). Ann. Entomol. Soc. Am. 82: 466-475.

RitLAND D.B. 1991: Revising a classic butterfly mimicry scenario - demonstration of Müllerian mimicry between Florida viceroys (Limenitis archippus floridensis) and queens (Danaus gilippus berenice). Evolution 45: 918-934.

RitLAND D.B. 1994: Variability of palatability inn queen butterflies (Danaus gilippus) and implications regarding mimicry. Ecology 75: 732-746.

ROPER T.J. 1990: Responses of domestic chicks to artificially coloured insect prey: effects of previous experience and background colour. Anim. Behav. 39: 466-473.

Rowe C., Lindström L. \& Lyytinen A. 2004: The importance of pattern similarity between Müllerian mimics on predator avoidance learning. Proc. R. Soc. (B) 271: 407-413.

Ruxton G.D., Franks D.W., Balogh A.C.V. \& Leimar O. 2008 Evolutionary implications of the form of predator generalization for aposematic signals and mimicry in prey. Evolution 62: 2913-2921.

Schlee M.A. 1986: Avian predation on Heteroptera: Experiments on the European blackbird Turdus m. merula L. Ethology 73: 1-18.
Schuh R.T. \& Slater J.A. 1995: True Bugs of the World (Hemiptera - Heteroptera). Classification and Natural History. Cornell University Press, Ithaca, 336 pp.

ScudDER G.G.E. \& Duffy S.S. 1972: Cardiac glycosides in the Lygaeinae (Hemiptera, Lygaeidae). Can. J. Zool. 50: 35-42.

SherRATt T.N. 2008: The evolution of Müllerian mimicry. Naturwissenschaften 95: 681-95.

Sillén-Tullberg B. 1985: Higher survival of an aposematic than of a cryptic form of a distasteful bug. Oecologia (Berlin) 67: 411-415.

Sillén-Tullberg B., Wiklund Ch. \& JÄrvi T. 1982: Aposematic coloration in adult and larvae of Lygaeus equestris and its bearing on müllerian mimicry: an experimental study on predation on living bugs by the great tit Parus major. Oikos 39: 131-136.

Skelhorn J. \& Rowe C. 2007: Automimic frequency influences the foraging decisions of avian predators on aposematic prey. Anim. Behav. 74: 1563-1572.

SPEED M.P. 1993: Müllerian mimicry and the psychology of predation. Anim. Behav. 45: 571-580.

SpeED M.P. 1999: Robot predators and virtual ecologies: the importance of memory in mimicry studies. Anim. Behav. 57: 203-213.

Stránský K., Valterová I., Ubik K., Čejka J. \& KřeČek J. 1998: Volatiles from stink bug, Graphosoma lineatum (L.), and from green shield bug, Palomena prasina (L.), (Heteroptera: Pentatomidae). J. High Res. Chromatog. 21: 475-476.

Svádová K., Exnerová A., Štys P., Landová E., Valenta J., FučíKovÁ A. \& Socha R. 2009: Role of different colours of aposematic insects in learning, memory and generalization of naive bird predators. Anim. Behav. 77: 327-336.

Tullberg B.S., Gamberale-Stille G. \& Solbreck C. 2000: Effects of food plant and group size on predator defence: differences between two co-occuring aposematic Lygaeinae bugs. Ecol. Entomol. 25: 220-225.

Wachmann E., Melber A. \& Deckert J. 2007: Wanzen, 3: Pentatomomorpha I. Die Tierwelt Deutschlands, 78. Goecke \& Evers, Keltern, 272 pp.

Wachmann E., Melber A. \& Deckert J. 2008: Wanzen, 4: Pentatomomorpha II. Die Tierwelt Deutschlands, 81. Goecke \& Evers, Keltern, 230 pp.

Wagner E. 1966: Wanzen oder Heteropteren I. Pentatomomorpha. Die Tierwelt Deutschlands, 54. VEB Gustav Fischer Verlag, Jena, 235 pp.

Received December 4, 2009; revised and accepted February 15, 2010 